\title{
An Analysis of Disability Representation in African Higher Education Policies
}

\author{
Fadzayi M. Maruza \\ University of the Western Cape, Republic of South Africa \\ Email: 3777831@myuwc.ac.za \\ Address: University of the Western Cape, Robert Sobukwe Road, Belville, 7535, Republic of South Africa
}

\section{Introduction}

In order to enhance understanding of the gap between policies and practice the aim of this research is to examine how disability policies are framed at the institutional level in African universities. Due to a lack of current scholarly work, institutional actors struggle to understand the experiences of students with disabilities who are pursuing higher education credentials (Barnes and Mercer 2004; Liasidou 2013). Globally, the policy response towards individuals with disability have changed (Beauchamp-Pryor 2012) and this has been seen in the widening participation of people with disability in Higher Education (HE). While this momentum is a laudable goal, the enthusiasm for universities to foster access for people with disability has gotten ahead of their understanding of how institutional policies and practices in African countries might be broadly crafted to achieve more access and participation of students with disability in HE (Howell 2006; Chitaika 2010; Mutswangwa 2014; Mutanga 2017). These progressive steps need to be placed under scrutiny so that they shed light on the gap between policy and practice in HE (Macleod and Cebula 2009; Moriña Díez, López, and Molina 2015). A major characteristic of the current HE research and policy context is that there is so much policy lending and borrowing (Lomofsky and Lazarus 2001; Kristensen et al. 2006).

While there is nothing inherently wrong with policy lending and borrowing, this research argues that there is a need to keep exploring more and nuanced ways to expand our understanding of the challenges facing African HE response to disability. The main question this research intends to answer is how is disability framed and implemented within current university policies at the University of Zimbabwe and the University of Cape Town? Thus, in answering the posed question, this research is engaging an approach to study policy issues on disability that will give an expansive but contextual approach relevant for Africa. To do this, the researchers are investigating the underlying assumptions about disability and how they influence the representation of students with disabilities in university policies. Such a study hopes to enhance understanding of policy and practice by looking into how disability is framed at the institutional level by comparing higher education systems in two African countries, namely South Africa and Zimbabwe. This study is at the point of unpacking how the representation of disability in university policies impacts actors (students, staff, faculty and others) in HE with disabilities.

\section{Research Objectives}

The main objectives of this research are (1) To explore how universities are defining, categorizing, and addressing disability in the policies; (2) to analyse the accomplishments of the policy representation of disability; and (3) to analyse the knowledge foundations that influenced the policy framing of disability.

\section{Research Questions}


The main research question for this study is to determine how student disability is represented within current university policies and practices at the University of Zimbabwe and the University of Cape Town. How is student disability represented within current university policies and practices at the University of Zimbabwe and the University of Cape Town? To illustrate the steps to be taken in the study to answer this research question, the following subquestions were developed:

1. How are universities defining and categorising disability in their university policies?

2. How are universities specifically addressing issues surrounding disability in their policies?

3. What have universities accomplished as a result of this policy representation of student disability?

4. What and whose knowledge influenced the framing of the policy representation?

\section{Conceptual Framework}

To gird the process of answering the above research questions, the study is being guided by institutional logics as the theory buttressing two frameworks, namely: "What's the problem represented to be" (WPR) and civic epistemology. Institutional logics are defined as socially-constructed sets of material practices, assumptions, values and beliefs that shape cognition and behaviour (Thornton, Ocasio, and Lounsbury 2012) and these logics guide institutions on how to act in particular situations. WPR is an approach to policy analysis developed by (Bacchi 1999). The framework claims that policies contain implicit representations of the 'problems' they appear to address. Bacchi (2009) notes that the questions in the framework allow for a critical engagement with a topic. Using WPR framework for this study will assist to subject disability representations in policies to critical scrutiny and unearth the underpinning notions. Civic epistemology framework will help in examining cultures and institutional practices that shape what kinds of knowledge count in policy processes and how this knowledge is evaluated (Jasanoff 2005). Miller (2005) notes that civic epistemologies are styles of knowledge making and thus have implications for how disability policies are constructed Miller (2005) and whose voice and assumptions are represented in policies.

\section{Research Methodology}

This research is a qualitative study utilizing a comparative design which is suitable for in-depth evaluation of complex issues (Creswell 2014). A cross-national comparative study will assist in examining institutional and contextual differences in how disability is represented in university policies in two different country contexts. The selected universities include the University of Zimbabwe established in 1952 and The University of Cape Town established in 1829. The two selected universities are the first and oldest universities in their countries. Both universities have colonial and apartheid historical legacies and as pioneering flagship institutions it will be interesting to reflectively critique disability policies at university level (Tight 2012; Teferra 2017). Comparing the disability policies of two universities in different countries will be particularly useful because our understanding of social phenomena can be enhanced when they are compared in relation to meaningfully contrasting situations Bryman (2004). It is also suitable for this study because the universities under study can better be understood within their historical, cultural, and social contexts rather than having a uniform study across all the two countries (Aggarwal and Gasskov 2013). Data is in the process of being collected using a policy analysis with documents being the main source of data, and they will be selected using purposive sampling to identify and interrogate the problem representations they contain. Documents that will be analyzed in this study include university policies, regulations annual reports and plans, white papers, policy manuals, websites, memoranda from meetings, mission statements, and strategic plans from each university. Interviews will also be used to allow for integration of political and social perspectives into one analysis (Creswell and Poth 2016). 5 University staff, eight students with and without disabilities for the interviews will be selected using purposive and snowballing sampling for two experts who contribute to 
disability policy framing in the selected universities. Semi-structured interviews with administrative staff from the disability units, student affairs department staff, and experts who contributed to the framing of the disability policy will be used to gain opinion about working with university disability policies. Fifteen interviewees from each university and country context will participate in the study making the total number of interviewees for the study 30 .

Lastly, a comparison of Zimbabwe and South Africa will allow for enough variables to be constant so that interesting points of similarity, difference, and possible causality can be focused on and thoroughly explained (Paige 1999; Mahoney and Rueschemeyer 2003). Therefore, a comparative study design will help obtain an in-depth description of issues, challenges and proposals related to how disability is represented in policy framing (Yin 2014) in the selected universities in Zimbabwe and South Africa.

\section{References}

Aggarwal, Ashwani. and Vladimir Gasskov 2013. Comparative analysis of national skills development policies: A guide for policy maker. Pretoria: ILO.

Bryman, Alan. 2004. Social research methods. $2^{\text {nd }}$ ed. Oxford: Oxford University Press.

Conducting mixed methods research. $2^{\text {nd }}$ ed. Thousand Oaks, CA: Sage.

Bacchi, Carol.1999. Women, Policy and Politics: The Construction of Policy Problems. London: SAGE.

Bacchi, Carol.2009. Analysing policy: What has the problem represented to be? French's Forest, NSW: Pearson Education.

Barnes, Carol and Mercer, G. 2004. "Theorising and researching disability from a social model perspective". In Implementing the Social Model of Disability: Theory and Research, edited by Barnes, C. and Mercer, G., 1-17. Leeds: The Disability Press.

Beauchamp-Pryor, Karen. 2012. "From absent to active voices: Securing disability equality within higher education." International Journal of Inclusive Education 16(3):283-295.

http://dx.doi.org/10.1080/13603116.2010.489120

Chataika, Tsitsi. 2010. Inclusion of Disabled Students in Higher Education in Zimbabwe. In Cross-cultural Perspectives on Policy and Practice: decolonizing community contexts, edited by J. Lavia \& M. Moore, 116-131. New York: Routledge.

Creswell, John.W. 2014. Research design: Qualitative, quantitative, and mixed methods approaches. Washington D.C: Sage publications.

Creswell, John.W and Cheryl N Poth. 2016. Qualitative Inquiry and Research Design. Singapore: Sage.

Moriña Díez, Anabel, Gavaria R. López, and Victor M Molina. 2015. "Students with disabilities in higher education: A biographical-narrative approach to the role of lecturers." Higher Education Research \& Development 34(1): 147159. http://dx.doi.org/10.1080/07294360.2014.934329.

Howell, Collen. 2006. Disabled students and higher education in South Africa. In Disability and social change, edited by B. Watermayer, L. Swartz, T. Lorenzo, M. Schneider, \& M. Priestley, 164-178. Cape Town: Human Sciences Research Council Press.

Jasanoff, Sheilla. 2005. Designs on Nature: Biotechnology Regulation in America and Europe. Princeton: Princeton University Press.

Kristensen, Kistern. et al. 2006. "Opportunities for inclusion: the education of learners with special educational needs and disabilities in special schools in Uganda." British Journal of Special Education 33(3):139-147.

Lomofsky, Lilian and Sandy Lazarus. 2001. "South Africa: First steps in the development of an inclusive education system." Cambridge Journal of Education 31(3): 303-317. 
Liasidou, Anastasia. 2013. "Intersectional understandings of disability and implications for a social justice reform agenda in education policy and practice." Disability \& Society 28(3): 299-312.

Macleod, Gale and K R Cebula 2009. "Experiences of disabled students in initial teacher education." Cambridge Journal of Education 39(4):457-472. http://dx.doi.org/10.1080/03057640903352465.

Mahoney, James and Rueschemeyer, Dietrich. 2003. Comparative Historical Analysis in the Social Sciences. Cambridge, UK: Cambridge University Press.

Miller, Clark. A. 2005. "New Civic Epistemologies of Quantification: Making Sense of Indicators of Local and Global Sustainability." Science, Technology, and Human Values 30(3): 403-32.

Mutanga, Oliver. 2017. "Inclusion of Students with Disabilities in South African Higher Education." International Journal of Disability. Development and Education.

Mutswanga, Peter. 2014. "An Exploration of the Inclusivity of Universities to People with Hearing Impairment in Zimbabwe.” The International Journal of Humanities \& Social Studies 2(9): 322-330.

Paige, Jeffery. 1999. "Conjuncture, Comparison, and Conditional Theory in Macrosocial Inquiry." American Journal of Sociology 105(3): 781-800.

Thornton, Patricia H; Wiliam Ocasio and Michael Lounsbury. 2012. The institutional logics perspective: A new approach to culture, structure, and process. Oxford, UK: Oxford University Press on Demand.

Teferra, Damtew. 2017. Flagship Universities in Africa. London. Palgrave Macmillan.

Tight, Malcom. 2012. Researching Higher Education. 2. ed. Maidenhead: Open Univ. Press.

Yin, Robert K. 2014. Case Study Research: Design and Methods. $5^{\text {th }}$ ed. Thousand Oaks: SAGE. 